\title{
Artistic and nonartistic backgrounds as determinants of the cognitive response to the arts
}

\author{
JOSEPH BILOTTA and MARTIN S. LINDAUER \\ State University of New York, College at Brockport, Brockport, New York 14420
}

\begin{abstract}
Three groups of artists, including dance and art students and art professors, did not differ from each other or from two groups of nonartists on physiognomic, imagery, aesthetic, and creativity measures. The 65 subjects' physiognomic perception did differ as a function of their aesthetic scores: Aesthetic subjects had higher physiognomic scores than nonaesthetic subjects. These results suggest that people's capacity to respond to the arts depends more on certain cognitive skills than on artistic training.
\end{abstract}

Comparisons between different types of artists (for example, between dancers and painters) and between artists and nonartists could add to our understanding of aesthetics (Lindauer, in press). Divergent backgrounds in the arts, or none at all, could be tied to cognitive capacities like those of imagery, physiognomic perception, and the like. These, in turn, could be the basis for the response to the arts (or to indifference).

Unfortunately, few studies have directly made these kinds of comparisons, probably because of the methodological difficulties involved. Several groups of artists and nonartists are required, along with multiple measures. Some of our work is relevant (summarized in Parsons \& Lindauer, in press), although it reflects a mixed picture. We obtained six measures from several groups of dancers and actors and from aesthetic and control subjects. Few differences between groups were found, and these were inconsistent: They varied with the specific groups compared and the specific measures used. For example, on one checklist of adjectives, all the artists as a group chose more words to describe their aesthetic experience than either aesthetic or control subjects. But on a different kind of checklist, only one of four groups of one type of artist (dancers with a great deal of training in classical ballet) chose more self-descriptive words than other groups. Furthermore, on one (but not another) aesthetic measure, a substantial number of nonartists scored as high as artists did. These and other similarly inconsistent findings led us to conclude that artistic background does not necessarily distinguish artists from each other or from nonartists on measures presumably related to artistic responsiveness.

The question then arises as to the reliability and generalizability of these findings: Would similar results be found, for these and other measures, for similar and other types of artistic and nonartistic groups? Physiognomic and imagery measures were of special interest because of their relationship to perception and cognition, processes considered important in aesthetics generally, in experimental aesthetics, and in creativity (Hungerland, 1957; Lund \& Anastasi, 1920; Lundin, 1956; Osborne, 1970). Curiously, however, neither imagery nor physiognomy has been clearly or unequivocally shown to be distinctive of artists (Lindauer, 1977; Rosett, Robbins, \& Watson, 1967, 1968). In addition to these measures, tests of aesthetics and creativity were also used. (The former were used in the earlier studies summarized above; Parsons \& Lindauer, in press). The four tests were given to dance and art undergraduate majors and, as a way of examining the role of experience in the arts, to art professors as well. The responses of these three art groups were compared with undergraduate psychology majors and science professors.

\section{METHOD}

Six groups of subjects $(N=65)$ were studied. Those with an art background included art professors and art and dance undergraduate majors $(\mathrm{N}=7,14$, and 9 , respectively). Nonartistic participants included professors drawn from several of the natural sciences $(\mathrm{N}=9)$ and two groups of undergraduate psychology majors $(\mathrm{N}=8$ and 18 , respectively; these two groups were combined after it was found they did not differ on any of the measures reported below). There were more women than men in the sample (41 and 24 , respectively), and they were unequally distributed among the groups.

Physiognomic perception was measured by the Stein (1975) Physiognomic Cue Test (PCT). It contains 33 line drawings. Subjects use a 6-point scale to rate the drawings either for their literal meanings (e.g., "seven lines") or for their physiognomic meanings. There are three types of physiognomy: feelings (e.g., a wavy line is "peaceful"), thing-like properties (e.g., seven lines are "the sun rising or setting"), and a total score that combines the previous two qualities (Factors A and B, respectively) with several other miscellaneous items.

The test of aesthetics was the New Aesthetic Test (Lindauer, Bode, Cruikshanks, Gardner, Kreily, Ribner, Seif, \& Smith, Note 1). It contains 36 statements that refer to a wide range of artistic and aesthetic activities. The greater the number of activities chosen as representative of the subject's interests, the higher was the aesthetic score. The measure of imagery was the Modal Imagery Test (Lindauer, 1977). Subjects rate the vividness of their imagery to 60 illustrative examples from six sensory 
modes (e.g., "your mother's voice [face]"). In addition to each of the six modal imagery scores, a seventh score is the total rating. A creativity test, the RAT, was also given (Mednick, 1962). The four measures were randomly arranged in a booklet.

The undergraduate students in the sample were contacted in their classes; the professors were contacted by phone and mail. The package of materials was completed at the subjects' convenience and returned, in most cases, within 2 weeks after distribution. The rate of return by art and science professors, although quite low despite several requests, was nevertheless about the same in each group (15\% and $16 \%$, respectively). The rate of return among the art, dance, and psychology undergraduate students was higher than that among the professors and was about equally distributed among the groups (33\%, $27 \%$, and $29 \%$, respectively).

\section{RESULTS}

The most direct way of comparing the five artistic and nonartistic groups is by examining their mean differences on each of the four measures (i.e., an analysis of variance). However, this analysis was unrevealing. On the physiognomy measure, no differences were found on the A (or feeling) factor $[F(4,60)=1.84, p>.05]$. While there were differences on the $\mathrm{B}$ (or meaning) factor and the total score $[F(4,60)=2.95$ and 2.81 , respectively, $p<.05]$, these were due to the performance of the two nonartistic groups: The psychology students scored higher than all the other groups, and the science professors scored lowest. A similarly unrevealing picture emerges for the imagery measure. No differences were found on the total imagery score or on five of the six modes $[F(4,60) \leqslant 2.06, p>.05]$. However, science professors did score lowest of all groups on the kinesthetic imagery mode $[F(4,60)=2.77, p<.05]$. There were several differences on the creativity measure $[F(4,60)=2.58, p<.05]$, but they were inconsistent: The science and art professors and art students had the lowest scores, and the dance and psychology students had the highest scores. The aesthetic scores did not differ between the groups $(F<1)$. Nor did the number of aesthetic subjects (i.e., those whose scores were above the median score on the New Aesthetic Test) differ between artistic and nonartistic groups $\left[\chi^{2}(4)=4.52\right.$, $\mathrm{p}>.05$ ]

The lack of any meaningful set of differences between types of artists and between artists and nonartists corroborated our earlier findings (Parsons \& Lindauer, in press). But even more important, our reluctance to prove the null hypothesis prompted further analyses. These led to some interesting and unexpected findings which were quite revealing about physiognomy and aesthetics. Distinct differences in physiognomic perception emerged, not as a function of artistic or nonartistic background, but instead, as a function of aesthetic scores.

Subjects were divided into aesthetic or nonaesthetic types, depending upon whether their scores fell above or below the median on the New Aesthetic Test, respectively. Aesthetic subjects had higher physiognomic scores than nonaesthetic subjects $[F(1,63)=5.47, p<.05]$ $x \rightarrow x$ High aesthetic subjects $0--0$ Low aesthetic subjects

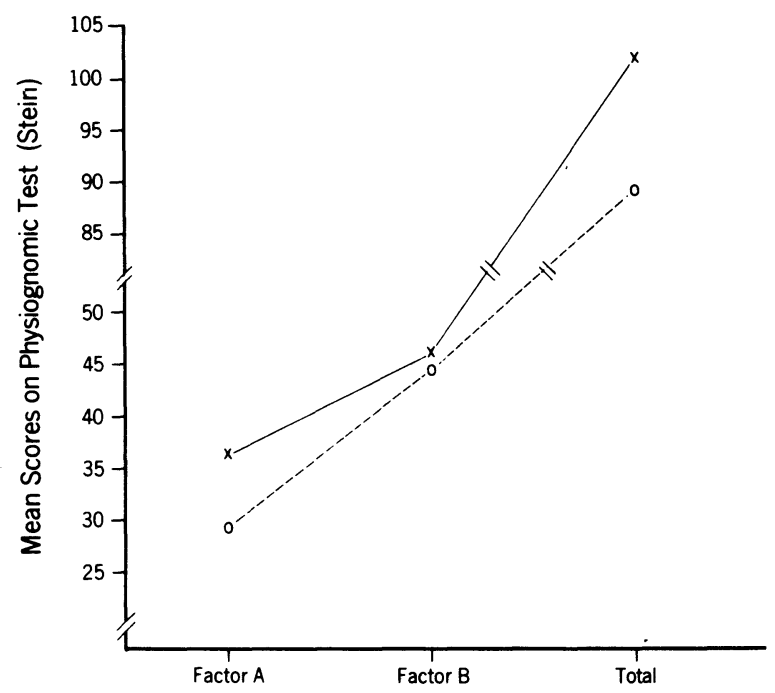

Figure 1. Physiognomic scores of aesthetic and nonaesthetic subjects.

(Figure 1). These differences depended upon the kind of physiognomy measured $[\mathrm{F}(2,126)=4.62, \mathrm{p}<.05]$ : They characterized the "feeling" aspect (Factor A) of physiognomy $[F(1,189)=4.06, p<.05$ and the total score $[F(1,189)=11.39, p<.01]$. Factor $B$ ("meaning") did not play a role $(\mathrm{F}<1)$. Thus, aesthetic persons were generally more physiognomically responsive to ordinary stimuli than were nonaesthetic persons, a distinction that did not depend on their artistic background.

The usefulness of the aesthetic distinction was indicated in other ways. Physiognomic and imagery measures, in those instances in which they were correlated, were correlated among the aesthetic subjects only. Thus, from two to four of the various sets of imagery scores were significantly correlated with either Factor $\mathbf{A}$ or the total physiognomic scores $(r \geqslant .31$, $\mathrm{p}<.05$, one-tailed test). Further, the single instance in which creativity and one of the six sets of imagery scores were significantly correlated $(r=.31, p<.05)$ was among the aesthetic subjects. [Not consistent with these trends, however, was the single significant correlation between the creativity score and Factor B of the physiognomic test: It was found among nonaesthetic subjects $(\mathrm{r}=.45, \mathrm{p}<.05)$.]

A similar analysis of physiognomy in terms of the subjects' imagery indicated some interesting findings not otherwise revealed by an analysis based on artistic background only. Subjects were categorized as either high or low imagizers, depending on whether their total imagery score fell either above or below, respectively, the overall median score. On this basis, all correlations between total imagery and each of the three physiognomy scores were significant among the high imagizers only $(r=.40-.82, p<.05)$; none was significant among 
low imagizers $(r=.18-.26, p>.05)$. (In contrast, correlations between imagery and physiognomy for each of the five groups achieved significance in only 1 of the 15 cases, and it was for a nonartistic group.) Distinctions between the three physiognomic scores on the basis of subjects' high or low imagery, although not statistically significant, however, did favor high imagizers $[\mathrm{F}(2,126)=1.58, \mathrm{p}>.05]$.

\section{DISCUSSION}

These results suggest that differences in cognitive processes, rather than differences in artistic training or background, distinguish subjects on measures presumably related to one's response to artistic stimuli. However, the presumed link between these measures and the response to the arts was not directly tested. Nor can we overlook the possibility that other measures (e.g., personality) may in fact distinguish artists from nonartists. These results do replicate and extend our earlier conclusions (Parsons \& Lindauer, in press) about the surprising equivalence, at least on some measures, between artistically trained and nontrained psople.

Several measures of cognition, obtained from several types of artistic and nonartistic groups, indicated that those in the arts are not necessarily more "skilled" than those not in the arts. Artists are not more physiognomic, aesthetic, creative, or better imagizers than nonartists. The key finding-that physiognomic perception varies as a function of aesthetic level-suggests that an audience's or observer's responsiveness to the arts may not depend on artistic training. Rather, taking a nonelitist and more democratic position, our responsiveness to the arts may depend less on special background and more on cognitive processes related to aesthetics, physiognomy, and imagery.

\section{REFERENCE NOTE}

1. Lindauer, M. S., Bode, P., Cruikshanks, R., Gardner, M. S., Kreily, J., Ribner, S., Seif, M., \& Smith, S. The self-defined aesthetic person: Sex and creativity distinctions. Paper presented at the 3rd Annual Genesee Valley Psychological Association, Rochester, New York, 1976.

\section{REFERENCES}

Hungerland, W. The aesthetic response reconsidered. Journal of Aesthetics and Art Criticism, 1957, 16, 32-43.

Lindauer, M. S. Imagery from the point of view of psychological aesthetics, the arts, and creativity. Journal of Mental Imagery, 1977, 1, 343-362.

Lindauer, M. S. Psychological aesthetics. In D. O'Hare (Ed.), Psychology and the arts. Sussex, England: Harvester, in press.

Lund, F. H., \& AnAstasi, A. An interpretation of aesthetic experience. American Journal of Psychology, 1920, 28, 434-448.

Lundin, R. W. Aesthetic experience or response? A psychological viewpoint. Psychological Record, 1956, 6, 28-32.

Mednick, S. A. The associative basis of the creative process. Psychological Review, 1962, 69, 209-213.

OsBorne, H. The art of appreciation. London: Oxford, 1970.

Parsons, C., \& Lindauer, M. S. Dance and theater: Their psychological cignificance and the aesthetics of their participants. Scientific Aesthetics, in press.

Rosett, H. L., Robbins, H., \& Watson, W. S. Standardization and construct validity of the Physiognomic Cue Test. Perceptual and Motor Skills, 1967, 24, 403-420.

Rosett, H. L., Robbins, H., \& Watson, W. S. Physiognomic perception as a cognitive control principle. Perceptual and Motor Skills, , 1968, 26, 707-719.

Stein, M. J. Physiognomic cue test manual. New York: Behavioral Publications, 1975.

(Received for publication March 27, 1980.) 